TABLE 1. Preoperative and postoperative patient characteristics

\begin{tabular}{|c|c|c|c|c|c|c|c|c|c|c|}
\hline \multirow[b]{2}{*}{ Patient } & \multicolumn{5}{|c|}{ Preoperative characteristics } & \multicolumn{5}{|c|}{ Postoperative characteristics } \\
\hline & $\begin{array}{l}\text { Catheter } \\
\text { ablation } \\
\text { in history }\end{array}$ & $\begin{array}{c}\text { Age } \\
(y)\end{array}$ & $\begin{array}{l}\text { Duration } \\
\text { of } A F(\mathbf{m o})\end{array}$ & $\begin{array}{c}\text { Atrial } \\
\text { size }(\mathrm{mm})\end{array}$ & $\begin{array}{l}\text { Discharge } \\
\text { (d) }\end{array}$ & Holter & Warfarin & $\begin{array}{c}\text { Antiarrhythmic } \\
\text { drugs }\end{array}$ & $\begin{array}{c}\text { Holter } \\
\text { follow-up (d) }\end{array}$ & Complication \\
\hline 1 & Yes & 61 & 72 & 50 & 5 & SR & No & No & 328 & No \\
\hline 2 & No & 65 & 60 & 43 & 7 & AF & Yes & Yes & 313 & No \\
\hline 3 & Yes & 56 & 228 & 55 & 8 & SR & No & No & 267 & $\begin{array}{l}\text { Paralysis of } \\
\text { hemidiaphram }\end{array}$ \\
\hline 4 & Yes & 39 & 156 & NA & 4 & SR & Yes & Yes & 312 & No \\
\hline 5 & No & 57 & 192 & 64 & 8 & AF & Yes & Yes & 301 & No \\
\hline 6 & No & 62 & 36 & NA & 9 & SR & No & No & 255 & $\begin{array}{l}\text { Paralysis of } \\
\text { hemidiaphram }\end{array}$ \\
\hline 7 & No & 59 & 36 & NA & 7 & SR & No & No & 246 & No \\
\hline 8 & Yes & 63 & 144 & 48 & 7 & SR & No & No & 284 & No \\
\hline 9 & No & 44 & 12 & 69 & 4 & SR & No & No & 244 & No \\
\hline Mean & $44 \%$ & $60 \pm 9$ & $72 \pm 72$ & $50 \pm 12$ & $7 \pm 2$ & $78 \%$ & $33 \%$ & $33 \%$ & $284 \pm 32$ & $22 \%$ \\
\hline
\end{tabular}

Warfarin and antiarrhythmic drug usage was noted for the day after Holter follow-up. NA, Not available; $A F$, atrial flutter; $S R$, sinus rhythm.

isolation is easily achieved in all patients under direct vision and is not time consuming after a short learning curve.

In conclusion, this is the first series of completely thoracoscopic bilateral pulmonary vein isolations and left atrial appendage exclusions for the treatment of atrial fibrillation, resulting in an excellent short-term outcome. This minimally invasive approach may contribute to a short-stay concept in the near future.

\section{References}

1. Wolf RK, Schneeberger EW, Osterday R, Miller D, Merrill W, Flege B Jr., et al. Video-assisted bilateral pulmonary vein isolation and left atrial appendage exclusion for atrial fibrillation. J Thorac Cardiovasc Surg. 2005; 130:797-802.

2. Sagbas E, Akpinar B, Sanisoglu I, Caynak B, Tamtekin B, Oral K, et al. Video-assisted bilateral epicardial pulmonary vein isolation for the treatment of lone atrial fibrillation. Ann Thorac Surg. 2007;83:1724-30.

3. Mokadam NA, McCarthy PM, Gillinov AM, Ryan WH, Moon MR, Mack MJ, et al. A prospective multicenter trial of bipolar radiofrequency ablation for atrial fibrillation: early results. Ann Thorac Surg. 2004;78: 1665-70.

4. Prasad SM, Maniar HS, Camillo J, Schuessler RB, Boineau BP, Sundt TM, et al. The Cox maze III procedure for atrial fibrillation: long-term efficacy in patients undergoing lone versus concomitant procedures. J Thorac Cardiovasc Surg. 2003;126:1822-7.

\title{
Dumbbell-shaped mediastinal neurogenic tumor forming a string-of-beads structure
}

Ryuichi Suemitsu, MD, PhD, Hironori Matsuzawa, MD, Masafumi Yamaguchi, MD, PhD, and Sadanori Takeo, MD, PhD, Fukuoka, Japan

From the Department of Thoracic Surgery, Clinical Research Institute, National Hospital Organization, Kyushu Medical Center, Fukuoka, Japan.

Received for publication Aug 1, 2007; accepted for publication Aug 30, 2007.

Address for reprints: Ryuichi Suemitsu, MD, PhD, Department of Thoracic Surgery, National Hospital Organization, Kyushu Medical Center, Jigyohama 1-chome, 8-1, Chuo-ku, Fukuoka City, Japan 810-8563 (E-mail: suemitsu@qmed.hosp.go.jp).

J Thorac Cardiovasc Surg 2008;136:522-3

$0022-5223 / \$ 34.00$

Copyright $\odot 2008$ by The American Association for Thoracic Surgery doi:10.1016/j.jtcvs.2007.08.082
A 38-year-old man had an abnormal shadow in the left upper lung field of a chest radiograph taken by his family physician. A chest computed tomographic scan showed a homogeneous tumor $10 \mathrm{~cm}$ in diameter with a string of 4 beads along the fourth intercostal space, originating from the posterior mediastinum and projecting from the spinal canal between the fourth and fifth thoracic vertebrae (Th4 and Th5). Magnetic resonance imaging revealed a thoracic dumbbell-shaped tumor producing spinal cord compression in the extradural space (Figure 1). Serum chemistry and blood counts were within normal limits and the patient had no paralytic symptoms or café-au-lait spots.

The operative findings were as follows. Under general anesthesia, the patient was intubated with a double-lumen endotracheal 


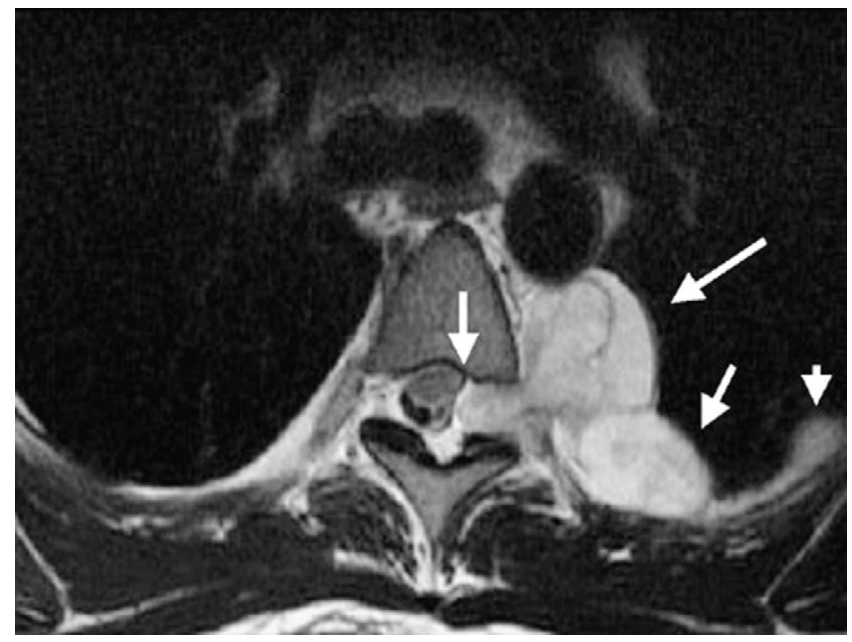

Figure 1. Chest magnetic resonance image revealed an anterior and posterior mediastinal tumor projecting from the spinal canal. The tumor compressed the thoracic spinal cord. A left arrow shows that the tumor has pressed the spine, and right three arrows show the tumor of a string-of-beads structure.

tube and was situated in the prone position. Initially, a vertical dorsal neck skin incision was made, exposing the Th3-5 spine. Laminectomy of Th4 was performed to release the tumor from the spinal cord, followed by an intervertebral foraminotomy using an air drill and microsurgery. The tumor was detected in the left extradural space and was pressing the spinal cord to the right side. The tumor originated from the Th4 posterior nerve roots and adhered to the surrounding tissue. The left neuroforamen of Th4 was obviously enlarged and the extradural tumor projected into the thoracic space. The spinal component of the tumor was cut from the posterior nerve roots of Th4 and resected. Subsequently, the patient was moved to the right lateral position and underwent thoracoscopic resection. In the left thoracic space, the tumor was observed along the fourth intercostal space. The tumor structure appeared as a string of 4 nodules, each 1.5 to $2.0 \mathrm{~cm}$ in each size (Figure 2, A). The tumor had not adhered to the surrounding tissue and was detected along with the intercostal nerve. The thoracic component of this tumor was resected by video-assisted thoracic surgery. All neurogenic tumors were completely resected after division into two components (Figure 2, B). Microscopic findings revealed the pathologic features of the extradural tumor to be schwannoma. The patient made an uneventful recovery after the operation.

\section{Discussion}

Mediastinal neurogenic tumors frequently appear in the posterior mediastinum, which accounts for $10 \%$ to $34 \%$ of all mediastinal tumors, and most adult cases are benign. ${ }^{1-4}$ In $9 \%$ to $10 \%$ of neurogenic tumors, the tumors have an intraspinal extension and are called dumbbell-shaped tumors. ${ }^{1,2,4}$ Isoda and associates ${ }^{1}$ reported magnetic resonance imaging findings of 19 cases with neurogenic tumors, in which cystic lesions $(77.8 \%)$ and a string-of-beads structure in the vertebral canal $(44.4 \%)$ were present. However, there was no report of a dumbbell-shaped tumor with a string-of-beads structure in the thoracic space; our case appears to be the first report of such an occurrence.
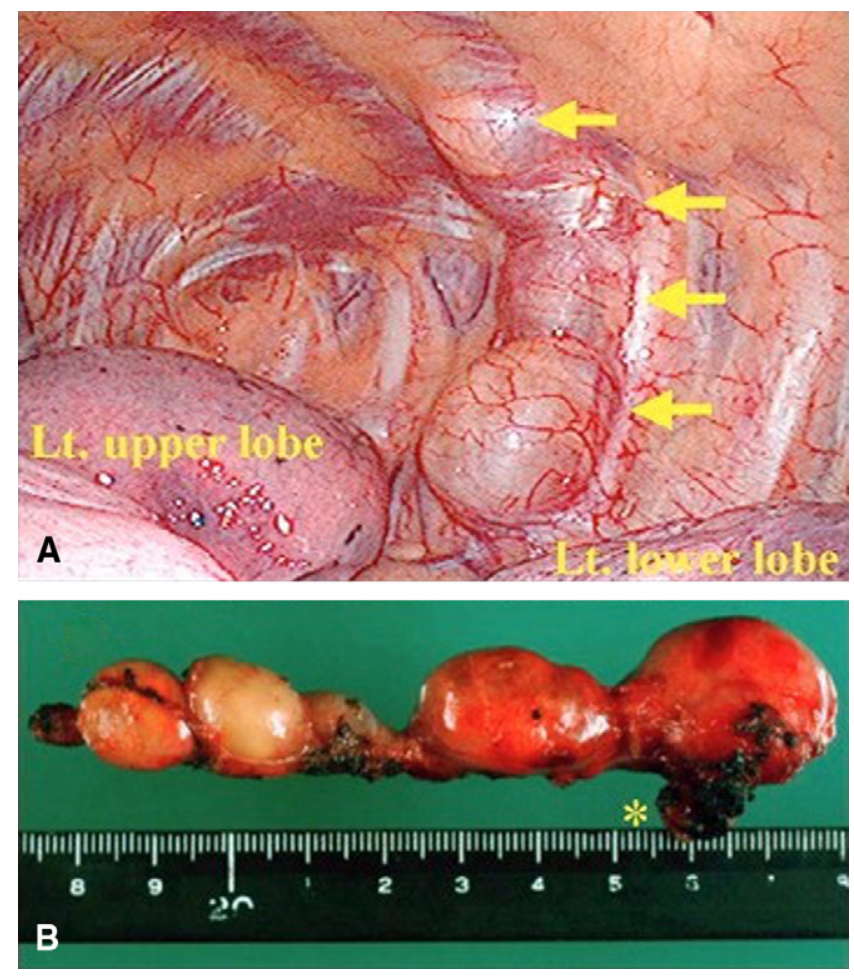

Figure 2. A, Operative finding. A 4-bead string of tumor nodules appeared in the fourth intercostal space. B, Macroscopic finding. Part of the extradural tumor length, about $10 \mathrm{~cm}$ in the thoracic space, formed a string of 4 beads. *Connection to a portion of the extradural tumor.

Neurogenic tumors of the thorax originate from the embryonic neural crest cells, which normally constitute the spinal ganglia, paraganglionic, and parasympathetic systems $s^{3,4}$ and are most often situated in the paravertebral area in connection with the sympathetic chain or intercostal nerves. Neurogenic tumors can also grow from the connective tissue constituting nerve sheaths and are observed in children and adults, with different patterns for each. ${ }^{4}$ In this case, the tumor originated from the intercostal nerve and formed a string-of-beads structure. The "beads" contained cells of the spindle type and the "string" was formed only with connective tissue. The cause of the formation of such a structure is uncertain.

We encountered a rare neurogenic dumbbell-shaped tumor that formed a string-of-beads structure in the thoracic space.

\section{References}

1. Isoda H, Takahashi M, Mochizuki T, Ramsey RG, Masui T, Takehara Y, et al. MRI of dumbbell-shaped spinal tumors. J Comput Assist Tomogr. 1996;20:573-82.

2. Takeda S, Miyoshi S, Minami M, Matsuda H. Intrathoracic neurogenic tumors-50 years' experience in a Japanese institution. Eur J Cardiothorac Surg. 2004;26:807-12.

3. Ribet ME, Cardot GR. Neurogenic tumors of the thorax. Ann Thorac Surg. 1994;58:1091-5.

4. Akwari OE, Payne WS, Onofrio BM, Dines DE, Muhm JR. Dumbbell neurogenic tumors of the mediastinum. Diagnosis and management. Mayo Clin Proc. 1978;53:353-8. 